\title{
Effect of Preventive Bundle Guidelines on Nurses' Knowledge and Compliance Regarding Pressure Ulcer Among Critically III Children at Pediatric Intensive Care Unit
}

\author{
Rawia Abd Elghany Mohamed*, Seham Mohamed Abd Elaziz, Hanan Nabawy Elaasar \\ Faculty of Nursing, Benha University, Benha, Egypt \\ Email address: \\ rawia.abdelghany@yahoo.com (R. A. E. Mohamed) \\ ${ }^{*}$ Corresponding author \\ To cite this article: \\ Rawia Abd Elghany Mohamed, Seham Mohamed Abd Elaziz, Hanan Nabawy Elaasar. Effect of Preventive Bundle Guidelines on Nurses' \\ Knowledge and Compliance Regarding Pressure Ulcer Among Critically Ill Children at Pediatric Intensive Care Unit. American Journal of \\ Nursing Science. Vol. 8, No. 5, 2019, pp. 243-254. doi: 10.11648/j.ajns.20190805.17
}

Received: July 17, 2019; Accepted: August 19, 2019; Published: September 25, 2019

\begin{abstract}
Pressure ulcers are a common and highly relevant professional care issues in pediatric intensive care units. The aim of this study was to evaluate the effect of preventive bundle guidelines on nurses' knowledge and compliance regarding pressure ulcer among critically ill children at Pediatric intensive care unit. Research design: A quasi-experimental design was used. Settings: This study was conducted at the pediatric intensive care unit in Benha Specialized Pediatric Hospital. Sample: A Convenient sample of nurses $(n=43)$ and purposive sample of critically ill children $(n=70)$ were included from the above mentioned setting. Those children were divided equally into two groups (study and control). Tools of data collection: Three tools were used namely; a structured interviewing questionnaire format, pressure ulcer preventive bundle compliance checklist and Braden Q Risk Assessment Scale. Results: Most children in the study group were not at risk of pressure ulcer in the first and second week of admission as well as before discharge than children in the control group. Moreover, the results revealed that there was significant improvement in nurses' knowledge regarding pressure ulcer as well as their compliance with preventive bundle guideline after bundle implementation. Conclusion: The implementation of preventive bundle guidelines proved to be effective in improving nurses' knowledge and their compliance, with a positive impact on the incidence of pressure ulcer among critically ill children. Recommendation: Preventive bundle guidelines should be implemented in pediatric intensive care units to reduce the harm associated with hospital-acquired pressure ulcer.
\end{abstract}

Keywords: Preventive Bundle Guidelines, Pressure Ulcer, Critically Ill Children, Pediatric Intensive Care Unit

\section{Introduction}

Pressure ulcer (PU) is an injury to skin or underlying tissue as a result of pressure or pressure with shear stress [1]. Pressure ulcer is localized damage to the skin or underlying soft tissue, usually over a bony prominence or related to a medical device or other equipment. Moreover, Pressure ulcer can present as intact skin or an open injury and may be painful. Such injuries occur as a result of intense and/or prolonged pressure or pressure in combination with shearing forces [2].

The prevalence of pressure ulcers in critically ill children widely varies and is reported at $0.8 \%$ to $27 \%$. Furthermore, children at greatest risk are those requiring mechanical ventilation or inotropic support; those who suffer a cardiac arrest following cardiac surgery; those with nutritional deficits and children with longer hospital lengths of stay. Medical device-associated pressure ulcers are frequent among pediatric patients with reported prevalence rates ranging from $50 \%$ to $69 \%$ [1].

Pressure ulcer reduces quality of life for children because of pain and infections, extend the length of hospital stay, and increase the cost of care. The period allocated for preventing pressure ulcer is shorter and less costly than that allocated for their care and treatment. Children in pediatric intensive care 
units (PICUs) are vulnerable to pressure ulcer that can cause significant mortality, thus emphasizing the need for effective prevention [3].

Incidence of pressure ulcer in children is generally reported as between $7 \%$ and $12 \%$ [4]. Furthermore, the rates range from $7 \%$ to $29 \%$ for children without preventive hospitalized in pediatric intensive care units (PICUs). Implementation of preventive interventions aimed to decrease pressure ulcer rate in high-risk pediatric critical care units has demonstrated the ability to decrease pressure ulcer rates to $6.8 \%$ [5].

The promotion of healthy, intact skin in the PICU was integrated into daily care. There was a focus on minimizing the layers of linen between the child's skin and pressure redistribution surface; implementation of disposable, absorbent under pads; and removal of disposable incontinent briefs from the PICU supply cart. These strategies were to emphasize continence promotion rather than managing incontinence, while optimizing the pressure redistribution air beds to their full effectiveness [6]. Maintaining skin integrity in the critical care environment is difficult because of child acuity and the highly invasive interventions and therapies they receive. Researchers of children pressure ulcer prevention suggest implementing a bundle of nursing interventions aimed at mitigating known risk factors as effective for preventing pressure ulcer. Prevention bundles address the highest risk factors for pressure ulcer which can include the presence of medical devices, moisture, nutrition, tissue, oxygenation, immobility, skin integrity, and support surface [7].

Pressure ulcer prevention bundles address the highest risk factors, which can include the presence of medical devices, moisture, tissue oxygenation, immobility, skin integrity, and support surface [7]. Immobilization, moist skin, critical illnesses, neurologic deterioration, malnutrition, infection, anemia, tissue perfusion or oxygen saturation changes, medication, and pressure caused by equipment may be risk factors that contribute to the deterioration of skin integrity. Consideration of these risk factors within the care-planning period is important in preventing pressure ulcer [2].

Effective preventive measures involve padding and careful positioning and fixation of medical devices attached to children, along with regular full skin assessment, in addition to the use of pressure relieving devices and management of the pertinent risk factors as poor skin condition and poor nutritional status [8]. Nevertheless, the ulcer in infants and children needs improvement, and more search is needed in this area [9].

Nursing interventions should address risk factors that were identified using the risk assessment and tailored to the child's individual needs. Interventions include pressure relief, specialized mattresses, dressing over bony prominences, monitoring devices, nutritional support and use of skin moisturizers. Moreover, the strategy for preventing pressure ulcer relies on two interdependent domains: pressure ulcer risk identification and pressure ulcer risk mitigation [10].

Nursing best practices prevent pressure injuries, including time-consuming, complex tasks that lack payment incentives. The Braden Scale is an evidence-based stratification tool the nurses use daily to assess pressure-injury risk [11].

Although the prevention of pressure ulcer is a multidisciplinary approach, nurses have an essential role in it through regular and thorough assessment and continuous child care [12]. This necessitates that nurses acquire related evidence - based knowledge and skills. Thus, nurse need training in related evidence based practices through evidence-linked educational programs focused on the pediatric population [13]. This study is an attempt to provide such training to intensive care pediatric nurses in the study setting.

\subsection{Significance of the Study}

Children admitted to intensive care units (ICUs) are at a higher risk of developing pressure ulcer than children admitted to general care. The International Pressure Ulcer Prevalence Survey indicated that facility-acquired pressure ulcer prevalence rates were highest $(12.1 \%)$ in the medical ICU [12]. Studies have reported an association between pressure ulcer and increased morbidity and mortality. Pressure ulcer can also lead to serious infectious complications, like bacteremia and sepsis. Because of these factors, Pressure ulcer are an important health problem for children in PICUs.

The pressure ulcer prevention bundle guide was effective in preventing pressure ulcer or reducing the risk of their occurrence. Wider use of literature-based care guides could improve nursing care, children outcomes, and reduce health care costs [2]. Hence, the researcher found urgent to implement preventive bundle guidelines to improve nurses' knowledge and compliance regarding pressure ulcer among critically ill children that could help to achieve positive outcomes.

\subsection{Aim of the Study}

The aim of this study was to evaluate the effect of preventive bundle guidelines on nurses' knowledge and compliance regarding pressure ulcer among critically ill children in Pediatric Intensive Care Unit through:

1. Assessing nurses' knowledge and compliance regarding pressure ulcer preventive bundle guidelines.

2. Designing and implementing preventive bundle guidelines for nurses who provide care to critically ill children based on pre intervention assessment.

3. Evaluating the effect of preventive bundle guidelines on nurses' knowledge and compliance.

4. Evaluating the effect of improved nurses' knowledge and compliance on reducing the occurrence of pressure ulcer risk for critically ill children.

\subsection{Research Hypothesis}

1. The level of nurses' knowledge and compliance will be improved significantly after implementing preventive bundle guidelines. 
2. There will be a statistically significant correlation between nurses' knowledge and compliance scores pre and post bundle implementation.

3. Critically ill children in study group who receive care after implementing preventive bundle guidelines will have less risk for pressure ulcer than those in control group who receive a routine hospital care.

\section{Subjects and Methods}

\subsection{Research Design}

A quasi-experimental design was utilized to achieve the aim of this study.

\subsection{Research Setting}

This study was conducted in pediatric intensive care unit (PICU) at Benha Specialized Pediatric Hospital affiliated to the ministry of health and population, it is found in the third floor and consisted of (3) rooms, first room contain (8) beds, second room contain (4) beds and the third room contain (1) bed named isolation room.

N. B The researcher doesn't conduct this study at Benha University hospital because the PICU in this hospital had some renovations and repairs during data collection time.

\subsection{Subjects}

The study subjects consisted of two groups:

First group: A Convenient sample of all available nurses $(n=43)$ working at the previously mentioned setting in morning and afternoon shifts regardless their personal characteristics.

Second group: A purposive sample of critically ill children $(n=70)$ were included from the previously mentioned setting. Those children were divided equally into 2 constructed groups; study group $(\mathrm{n}=35)$ who receive care after implementing preventive bundle guidelines and control group $(n=35)$ who receive a routine hospital care.

The inclusion criteria: Critically ill children.

The exclusion criteria: Children who had pressure ulcer on admission.

\subsection{Tools of Data Collection}

\subsubsection{Tool I}

A structured interviewing questionnaire format: It was designed by the researchers after reviewing of the related literatures, it was written in an Arabic language. It comprised three main parts which are:

Part I: Personal characteristics of the studied nurses such as; age, gender, academic qualification, years of experience, attendance of training courses related to pressure ulcer.

Part II: Personal characteristics of the studied children such as; age, gender, diagnosis, length of hospital stay at PICU and previous pressure ulcer of them.

Part III: Nurses' knowledge regarding pressure ulcer: It includes 14 multiple choice questions. Scoring system for knowledge: Nurses' knowledge were evaluated upon completion of the interview questionnaire as the studied nurses' knowledge was checked with a model key answer and accordingly, the complete correct answer was given two scores, the incomplete correct answer was given one score and zero for incorrect or don't know answers. The total score was ranged from $0-28$. Then, their total knowledge were categorized as score of $75 \%$ and more was considered good, a score between $50 \%$ to less than $75 \%$ was considered average, while a score below $50 \%$ was considered poor.

\subsubsection{Tool II}

Pressure ulcer prevention bundle compliance checklist: It was adopted from [14] to assess nurses' compliance towards pressure ulcer preventive bundle guidelines. It includes 18 steps and covered six dimensions named: Head to toe skin assessment (5 items), Medical devices care (3 items), Child positioning and bed elevation (3 items), Appropriate support surface (3 items), Moisture management (2 items) and Nutritional assessment (2 items).

Scoring system for pressure ulcer prevention bundle compliance checklist: Give a score of (two) for comply satisfactory, a score of (one) for comply unsatisfactory and a score of (zero) for not comply. Total scores converted into percent scores, where the score of $\geq 80 \%$ considered a satisfactory level of compliance and a score $<80 \%$ considered an unsatisfactory level of compliance.

\subsubsection{Tool III}

Pressure ulcer risk assessment using the Braden Q Risk Assessment Scale: It was validated and developed by [15] for predicting pressure ulcer risk for critically ill children. It consisted of six subscales named; mobility, activity, sensory perception, moisture, friction/shear, and nutrition. Each subscale is rated one- to four- point rating scale, each subscales, contain four categories, with the lowest number representing the highest risk. Total scores range from (9-18) scores with 9 or less than 9 putting a child at the highest risk for skin ulcer and more than 18 with no risk. The scores of all items were summed-up and divided as the following: severe risk (9 or below) high risk (10-12), moderate risk (13-14) mild risk (15-18) and no risk (more than 18) scores.

\subsection{Preparatory Phase}

A review of the past and currently available literatures related to the research problem using books, evidence-based articles, periodicals, and magazines were done to be acquainted with all aspects of the study problem and also in order to develop relevant tools for data collection and designing the content of the preventive bundle guidelines. This period extended from the beginning of June 2018 to the end of July 2018.

\subsection{Tool Validity and Reliability}

Tools validity was tested through a jury of three experts in pediatric nursing field to test the tool clarity, relevance, comprehensiveness, simplicity and applicability. 
Modifications of the tools were done according to the expert's judgment on the clarity of sentences, appropriateness of content and sequence of items. The experts agreed on the content, according to their review and minor modifications were done in the contents. Testing reliability of all items of the tools was done by using Cronbach's alpha test. It was 0.789 for knowledge and 0.871 for compliance checklist. This phase took one month August 2018.

\subsection{Ethical Considerations}

A permission to carry out the study was obtained from the hospital manager and the supervisor of intensive care unit in the previously mentioned study setting through submission of an official letter issued from the Dean of Faculty of Nursing, Benha University. All participants were assured that participation in the study was voluntary; each nurse was informed about the purpose, procedure, benefits and nature of the study and each nurse had the right to withdraw from the study at any time without any rationale, then oral consent obtained from them. Nurses were informed that obtained data will not be included in any further researches. Confidentiality and anonymity of each subject was assured through coding of all data and all information has taken was protected.

\subsection{Pilot Study}

The pilot study was carried out on 4 nurses and 8 children ( 4 for study and 4 for control groups) representing $10.0 \%$ of the study subject over a period of one month (September, 2018). The purpose was to ascertain the feasibility of the study, the clarity, and applicability of the tools. It also helped to estimate the time needed for filling out the forms. Based on the results of the pilot, the necessary modifications on the study tools were done and pilot study subjects were included in the study sample.

\subsection{Field Work}

The actual field work was carried out from the beginning of October 2018 to the end of March 2019. The researchers were available at the previously mentioned setting three days/week (Monday, Tuesday and Wednesday) in the pediatric intensive care unit in the morning shift to collect data by using the previous tools.

\subsubsection{Assessment Phase}

At the beginning, the researchers interview each nurse, introduced themselves to each participant included in the study, explained the aim of the study, duration, and activities and took an oral consent to participate in the study prior data collection. Then, each nurse was asked to fill the data collection tool individually to collect baseline data and to assess nurses' needs (Tool I). Then, the researchers observed each nurses' practice during demonstrating routine skin care for critically ill children to measure bundle compliance (Tool II). Meanwhile, The researchers started to assess children skin condition for risk of pressure ulcer in the control group after receiving routine hospital skin care by nurses weekly for three times $\left(1^{\text {st }}\right.$ week of admission, $2^{\text {nd }}$ week of admission and before discharge) by using Braden Q scale (Tool III)). This phase took about two months.

\subsubsection{Planning Phase}

The preventive bundle guidelines were designed by the researchers after an extensive review of related literatures and the needs identified in the assessment phase. An Arabic booklet concerning pressure ulcer preventive bundle guidelines was prepared and given to nurses.

\subsubsection{Implementation Phase}

The preventive bundle guidelines were implemented in about two months. It was carried out in 6 sessions (2 sessions for theory and 4 sessions for practice). A time schedule suitable for nurses was developed to conduct the sessions includes; date, place, topic, time and duration of each session. The training sessions consisted of two parts, the theoretical part and the practical parts cover the items of preventive bundle. It was difficult to take all nurses at the same time; thus they were divided into 8 groups of about 5-6 nurses in every session (five groups each group include five nurses and three groups each group include six nurses).

The duration of theory sessions 30-35 minutes for each session and practical sessions ranged between 45 to 60 minutes for three days/week. At the beginning of each session, the researchers started by a summary about what was given through the previous session and objectives of the new one, taking into consideration using simple and clear language to suit the nurses. Different teaching methods were used including small group discussion, lectures, brain storming, role-playing, demonstration, and re-demonstration. The teaching aids used were colored posters and Power Point presentation. Each nurse of all studied groups obtained a copy of preventive bundle handout explaining all elements in an Arabic language.

\subsubsection{Evaluation Phase}

After the completion of the guidelines contents; the nurses' knowledge and their compliance with preventive bundle guidelines were evaluated immediately after implementing preventive bundle guidelines, the post tests were administered by using same pretest tools. Additionally, the researchers asked nurses to apply preventive bundle guidelines on children (study group) and evaluate their skin condition for risk of pressure ulcer for three times ( $1^{\text {st }}$ week of admission, $2^{\text {nd }}$ week of admission and before discharge) by Braden Q scale (tool III). This phase took about two months.

\subsection{Statistical Analysis of Data}

The collected data were categorized, analyzed and tabulated using the SPSS computer program Version 21. Numerical data were expressed as the mean and standard deviation. Qualitative data were expressed as frequency and percentage. A comparison between qualitative variables carried out by using a parametric Chi-square test. Correlation among variables was done using Pearson correlation 
coefficient. A statistically significant difference was considered at $\mathrm{p}$-value $<0.05$, a highly statistically significant difference was considered at $\mathrm{p}$-value $\leq 0.001$ and no statistically significant difference was considered at pvalue $>0.05$.

\section{Results}

Table 1 shows the nurses' personal characteristics; it was observed that, the mean age of the studied nurses was $28.95 \pm 4.93$ years and the majority $(86 \%)$ of them were females. In relation to nurses' education more than one third $(34.9 \%)$ of them had a technical institute of nursing. Additionally, it was noticed that, two fifth (41.9\%) of nurses had an experience more than 8 years.

Table 2 shows children's characteristics, it was observed that, the mean age of the studied children was $5.8857 \pm 4.20624 \& 5.8571 \pm 4.38005$ in study group and control group respectively. It indicated that, there was no statistical significant difference $(\mathrm{P}>0.05)$ between the studied children.

Table 3 reveals nurses' knowledge regarding pressure pre and post intervention of the bundle implementation. It was found that, there was a statistically significant difference pre and post bundle implementation in most items.

Table 4 reveals nurses' compliance regarding pressure pre and post intervention of the bundle implementation. It was found that, there was a statistically significant difference and highly statistical significant difference pre and post bundle implementation in most items.

Table 5 indicated that there were highly statistical significant differences $(\mathrm{P}<0.001)$ between the studied nurses regarding total knowledge and compliance level pre and post intervention.

Table 6 elaborates appositive correlation between nurses' knowledge and compliance score in pre and post intervention.

Table 7 demonstrates that approximately less than half $(45.7 \% \& 40 \%)$ of children in the study group were not at risk of pressure ulcer in the first and second week of admission respectively; this was increased to $48 \%$ before discharge. On the other hand, around $(37.1 \%)$ of children in the control group were at high risk from the first week of admission, there was a statistically significant difference between study and control groups regarding stages of pressure ulcer $(\mathrm{P} \leq 0.05)$.

Figure 1 illustrates that, more than two thirds $(67.4 \%)$ of the studied nurses not attended any previous training courses regarding pressure ulcer, while less than one third (32.6\%).

Figure 2 shows obstacles of applying preventive bundle guidelines as reported by nurses. It was revealed that, a high workload, and insufficient resources were the most common barrier to applying preventive bundle guidelines in Pediatric Intensive Care Unit $(34.9 \%$ \& $30.2 \%)$ respectively. While $18.6 \%$ had no obstacles.

Figure 3 portrays that, more than one third of the studied children $(42.9 \%$ \& $37.1 \%)$ stay in hospital equal or more than
30 days.

Figure 4 displays that the majority of the studied children in both group had no previous pressure ulcer.

Table 1. Distribution of the studied nurses according to their personal characteristics $(n=43)$.

\begin{tabular}{lll}
\hline \multirow{2}{*}{ Characteristics } & \multicolumn{2}{l}{ Study sample $\mathbf{n}=\mathbf{4 3}$} \\
\cline { 2 - 3 } & No & $\mathbf{\%}$ \\
\hline Age in years & & \\
$20->25$ & 10 & 23.2 \\
$25->30$ & 15 & 34.9 \\
$30->35$ & 14 & 32.6 \\
$\geq 35$ & 4 & 9.3 \\
Mean \pm SD & $28.95 \pm 4.93$ \\
Gender & \multicolumn{2}{|c}{} \\
Male & 6 & 14.0 \\
Female & 37 & 86.0 \\
Academic qualification & \multicolumn{2}{|c}{} \\
Diploma of secondary technical nursing school & 14 & 32.6 \\
Diploma of technical institute of nursing & 1 & 2.3 \\
Technical institute of nursing & 15 & 34.9 \\
Bachelor of nursing science & 9 & 20.9 \\
Post graduate & 4 & 9.3 \\
Years of experience at pediatric intensive care unit & \multicolumn{2}{|c}{} \\
$>2$ years & 5 & 11.6 \\
2 $>5$ & 8 & 18.6 \\
$5>8$ & 12 & 27.9 \\
$\geq 8$ years & 18 & 41.9 \\
Mean \pm SD & $5.72 \pm 2.68$ \\
\hline
\end{tabular}

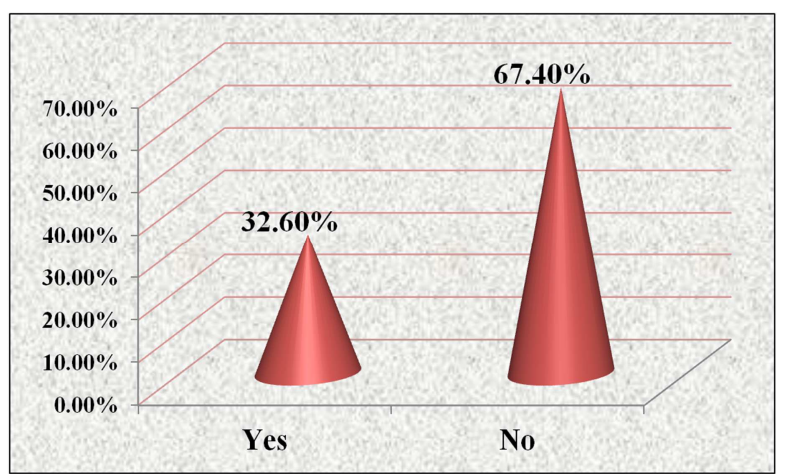

Figure 1. Distribution of the studied nurses according to their attendance to any previous training courses regarding pressure ulcer $(N=43)$.

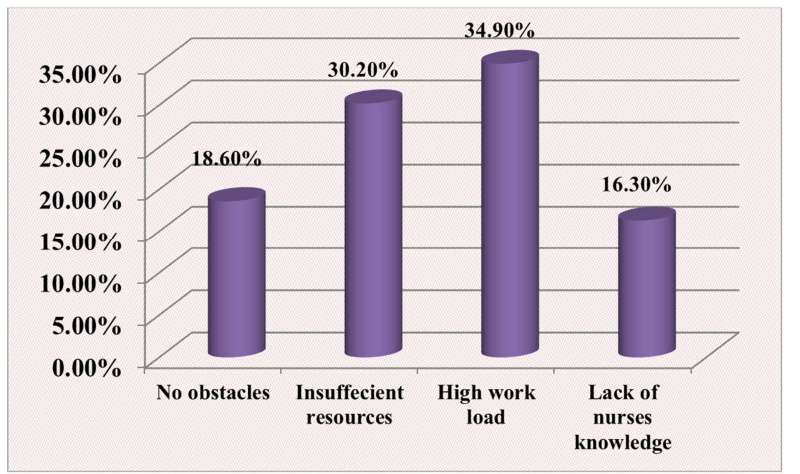

Figure 2. Obstacles of applying preventive bundle guidelines as reported by nurses $(N=43)$. 
Table 2. Distribution of the studied children according to their personal characteristics $(N=70)$.

\begin{tabular}{|c|c|c|c|c|c|c|}
\hline \multirow{2}{*}{ Characteristics } & \multicolumn{2}{|c|}{ Study group } & \multicolumn{2}{|c|}{ Control group } & \multirow{2}{*}{$X^{2}$} & \multirow{2}{*}{ P value } \\
\hline & No & $\%$ & No & $\%$ & & \\
\hline \multicolumn{7}{|l|}{ Age in years } \\
\hline $1>6$ & 19 & 54.3 & 20 & 57.2 & \multirow{4}{*}{0.350} & \multirow{4}{*}{$>0.05$} \\
\hline $6>12$ & 10 & 28.6 & 11 & 31.4 & & \\
\hline $12 \geq 18$ & 6 & 17.1 & 4 & 11.4 & & \\
\hline Mean \pm SD & \multicolumn{2}{|c|}{$5.8857 \pm 4.20624$} & \multicolumn{2}{|c|}{$5.8571 \pm 4.38005$} & & \\
\hline \multicolumn{7}{|l|}{ Gender } \\
\hline Male & 19 & 54.3 & 21 & 60.0 & \multirow[t]{3}{*}{2.422} & \multirow[t]{2}{*}{$>0.05$} \\
\hline Female & 16 & 45.7 & 14 & 40.0 & & \\
\hline \multicolumn{6}{|l|}{ Diagnosis } & \\
\hline Pneumonia & 14 & 40.0 & 11 & 31.4 & \multirow{7}{*}{0.539} & \multirow{7}{*}{$>0.05$} \\
\hline Convulsion & 7 & 20.0 & 6 & 17.1 & & \\
\hline Meningitis & 3 & 8.6 & 4 & 11.4 & & \\
\hline Hoffman & 2 & 5.7 & 0 & 0.0 & & \\
\hline Cerebral palsy & 6 & 17.1 & 9 & 25.8 & & \\
\hline Diabetic ketoacidosis & 1 & 2.9 & 2 & 5.7 & & \\
\hline Trauma & 2 & 5.7 & 3 & 8.6 & & \\
\hline
\end{tabular}

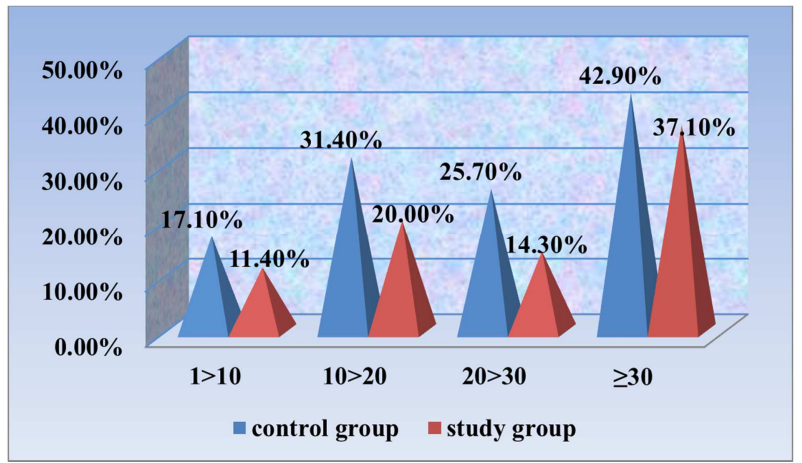

Figure 3. Length of hospital stay of the studied children $(N=70)$.

(Mean $\pm \mathrm{SD}=27.514 \pm 14.48807$ in control group\& $26.3143 \pm 16.611107$ in study group)

Table 3. Distribution of the studied nurses according to their knowledge regarding pressure ulcer pre and post intervention (N=43).

\begin{tabular}{|c|c|c|c|c|c|c|}
\hline \multirow{3}{*}{ Knowledge items } & \multicolumn{6}{|c|}{ Pre intervention $(n=43)$} \\
\hline & \multicolumn{2}{|c|}{ Complete correct answer } & \multicolumn{2}{|c|}{ Incomplete correct answer } & \multicolumn{2}{|c|}{ Incorrect answer/ don't know } \\
\hline & No & $\%$ & No & $\%$ & No & $\%$ \\
\hline 1- Definition of pressure ulcer & 12 & 27.9 & 13 & 30.2 & 18 & 41.9 \\
\hline 2- Causes of pressure ulcer development & 6 & 14.0 & 19 & 44.2 & 18 & 41.9 \\
\hline 3- Types of pressure ulcer & 10 & 23.3 & 12 & 27.9 & 21 & 48.8 \\
\hline 4- Pressure ulcer prevention & 11 & 25.6 & 6 & 14.0 & 26 & 60.5 \\
\hline 5- Common sites of pressure ulcer & 6 & 14.0 & 13 & 30.2 & 24 & 55.8 \\
\hline 6- Risk factors of pressure ulcer development & 8 & 18.6 & 13 & 30.2 & 22 & 51.2 \\
\hline 7- Nursing role in management of pressure ulcer & 3 & 7.0 & 22 & 51.2 & 18 & 41.9 \\
\hline 8- Degrees of pressure ulcer & 10 & 23.3 & 8 & 18.6 & 25 & 58.1 \\
\hline 9- Methods of skin assessment & 7 & 16.3 & 13 & 30.2 & 23 & 53.5 \\
\hline 10- Time of skin assessment & 7 & 16.3 & 14 & 32.6 & 22 & 51.2 \\
\hline 11- Child positioning & 9 & 20.9 & 17 & 39.5 & 17 & 39.5 \\
\hline $\begin{array}{l}\text { 12- Different methods of skin protection from } \\
\text { pressure ulcer }\end{array}$ & 12 & 27.9 & 19 & 44.2 & 12 & 27.9 \\
\hline 13- Bed elevation technique & 8 & 18.6 & 10 & 23.3 & 25 & 58.1 \\
\hline $\begin{array}{l}\text { 14- Importance of pressure ulcer reduction using } \\
\text { appropriate bed surface }\end{array}$ & 11 & 25.6 & 9 & 20.9 & 23 & 53.3 \\
\hline
\end{tabular}

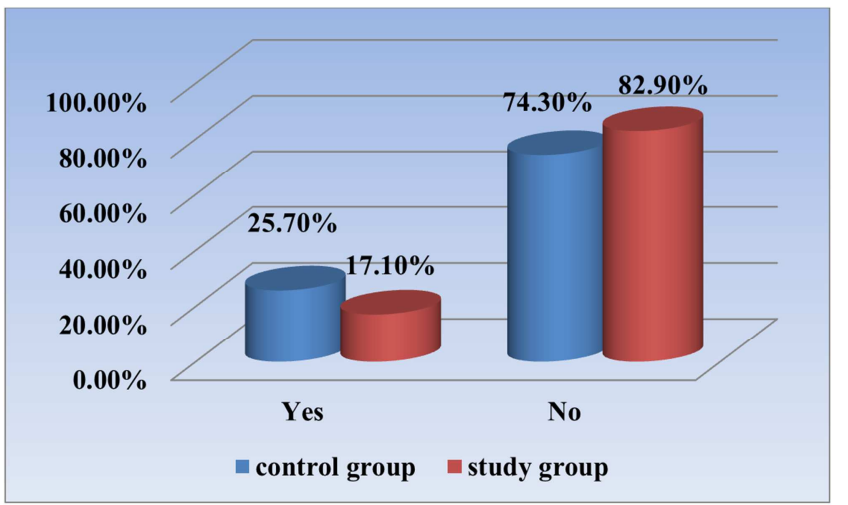

Figure 4. Previous pressure ulcer of the studied children $(N=70)$. 
Table 3. Continued.

\begin{tabular}{|c|c|c|c|c|c|c|c|c|}
\hline \multirow{3}{*}{ Knowledge items } & \multicolumn{6}{|c|}{ Post intervention $(n=43)$} & \multirow{3}{*}{$\mathbf{X}^{2}$} & \multirow{3}{*}{ P value } \\
\hline & \multicolumn{2}{|c|}{$\begin{array}{l}\text { Complete correct } \\
\text { answer }\end{array}$} & \multicolumn{2}{|c|}{$\begin{array}{l}\text { Incomplete correct } \\
\text { answer }\end{array}$} & \multicolumn{2}{|c|}{$\begin{array}{l}\text { Incorrect answer/ } \\
\text { don't know }\end{array}$} & & \\
\hline & No & $\%$ & No & $\%$ & No & $\%$ & & \\
\hline 1- Definition of pressure ulcer & 27 & 62.8 & 14 & 32.6 & 2 & 4.7 & 14.841 & $.005(\mathrm{P}<0.05)^{*}$ \\
\hline 2- Causes of pressure ulcer development & 29 & 67.4 & 10 & 23.3 & 4 & 9.3 & 12.57 & $.014(\mathrm{P}<0.05)^{*}$ \\
\hline 3- Types of pressure ulcer & 37 & 86.0 & 4 & 9.3 & 2 & 4.7 & 7.305 & $.121(\mathrm{P}>0.05)$ \\
\hline 4- Pressure ulcer prevention & 26 & 60.5 & 14 & 32.6 & 3 & 7.0 & 6.484 & $.166(\mathrm{P}>0.05)$ \\
\hline 5- Common sites of pressure ulcer & 24 & 55.8 & 17 & 39.5 & 2 & 4.7 & 14.645 & $.005(\mathrm{P}<0.001)^{* *}$ \\
\hline 6- Risk factors of pressure ulcer development & 27 & 62.8 & 15 & 34.9 & 1 & 2.3 & 2.371 & $.668(\mathrm{P}>0.05)$ \\
\hline 7- Nursing role in management of pressure ulcer & 26 & 60.5 & 15 & 34.9 & 2 & 4.7 & 5.059 & $.281(\mathrm{P}>0.05)$ \\
\hline 8- Degrees of pressure ulcer & 21 & 48.8 & 13 & 30.2 & 9 & 20.9 & 21.982 & $.000(\mathrm{P}<0.001)^{* *}$ \\
\hline 9- Methods of skin assessment & 36 & 83.7 & 0 & 0.0 & 7 & 16.3 & 7.271 & $.026(\mathrm{P}<0.05)^{*}$ \\
\hline 10- Time of skin assessment & 37 & 86.0 & 0 & 0.0 & 6 & 14.0 & 6.656 & $.036(\mathrm{P}<0.05)^{*}$ \\
\hline 11- Child positioning & 40 & 93.0 & 2 & 4.7 & 1 & 2.3 & 4.679 & $.322(\mathrm{P}>0.05)$ \\
\hline $\begin{array}{l}\text { 12- Different methods of skin protection from } \\
\text { pressure ulcer }\end{array}$ & 26 & 60.5 & 16 & 37.2 & 1 & 2.3 & 15.4 & $.004(\mathrm{P}<0.001)^{* *}$ \\
\hline 13- Bed elevation technique & 34 & 86.0 & 3 & 7.0 & 6 & 14.0 & 8.948 & $.062(\mathrm{P}<0.05)^{*}$ \\
\hline $\begin{array}{l}\text { 14- Importance of pressure ulcer reduction using } \\
\text { appropriate bed surface }\end{array}$ & 39 & 90.7 & 2 & 4.7 & 2 & 4.7 & 3.206 & $.524(\mathrm{P}>0.05)$ \\
\hline
\end{tabular}

A highly statistical significant at $\mathrm{P}$ value $<0.001^{* *}$, A statistically significant difference $(\mathrm{P}<0.05)^{*}$, no statistically significant difference $(\mathrm{P}>0.05)$

Table 4. Distribution of the studied nurses according to their compliance regarding pressure ulcer preventive bundle pre and post intervention (N=43).

\begin{tabular}{|c|c|c|c|c|c|c|}
\hline \multirow{3}{*}{ Compliance items } & \multicolumn{6}{|c|}{ Pre intervention $(n=43)$} \\
\hline & \multicolumn{2}{|c|}{$\begin{array}{l}\text { Comply } \\
\text { satisfactory }\end{array}$} & \multicolumn{2}{|c|}{ Comply unsatisfactory } & \multicolumn{2}{|c|}{ Not comply } \\
\hline & No & $\%$ & No & $\%$ & No & $\%$ \\
\hline $\begin{array}{l}\text { 1-Head to toe skin assessment } \\
\text { a. A comprehensive skin assessment on admission and then at least every shift. }\end{array}$ & 2 & 4.7 & 9 & 20.9 & 32 & 74.4 \\
\hline b. Risk assessment should be done at least daily. Using the Braden Scale. & 7 & 16.3 & 9 & 20.9 & 27 & 62.8 \\
\hline c. Perform physical examination of skin on each turning/reposition maneuver. & 2 & 4.7 & 10 & 23.3 & 31 & 72.1 \\
\hline d. Assess skin colour, turgor, moisture status, temperature & 2 & 4.7 & 11 & 25.6 & 30 & 69.8 \\
\hline e. Document skin assessment in the child's medical record & 6 & 14.0 & 16 & 37.2 & 21 & 48.8 \\
\hline 2-Medical Devices Care & & & & & & \\
\hline $\begin{array}{l}\text { a. Assess skin in contact with medical devices each shift or more frequently with } \\
\text { other care }\end{array}$ & 7 & 16.3 & 15 & 34.9 & 21 & 48.8 \\
\hline b. Rotate pulse oximeter every 8 hours or more often able & 2 & 4.7 & 29 & 67.4 & 12 & 27.9 \\
\hline $\begin{array}{l}\text { c. Examine the skin under equipment with routine removal (e.g., restraints, } \\
\text { splints, oxygen tubing, endotracheal tubes). }\end{array}$ & 2 & 4.7 & 20 & 46.5 & 21 & 48.8 \\
\hline $\begin{array}{l}\text { 3-Child positioning and bed elevation } \\
\text { a. Turn all immobile children at least every } 2 \text { hours }\end{array}$ & 0 & 0.0 & 0 & 0.0 & 43 & 100 \\
\hline $\begin{array}{l}\text { b. If the child spends a lot of time in bed, try to move him at least once every } \\
\text { shift. If possible }\end{array}$ & 2 & 4.7 & 21 & 48.8 & 20 & 46.5 \\
\hline c. Maintain head of bed less than or equal 30 degree unless contraindicated & 3 & 7.0 & 15 & 34.9 & 25 & 58.1 \\
\hline $\begin{array}{l}\text { 4-Appropriate support surface } \\
\text { a. Use pillows or pressure reduction devices to cushion bony prominences }\end{array}$ & 4 & 9.3 & 13 & 30.2 & 26 & 60.5 \\
\hline $\begin{array}{l}\text { b. Each time you lift a child or provide care, look at the exposed skin, especially } \\
\text { on bony prominences }\end{array}$ & 3 & 7.0 & 30 & 69.8 & 10 & 23.3 \\
\hline $\begin{array}{l}\text { c. Pay special attention to areas where the child lacks sensation to feel pain or } \\
\text { has had a breakdown in the past }\end{array}$ & 3 & 7.0 & 26 & 60.5 & 14 & 32.6 \\
\hline $\begin{array}{l}\text { 5-Moisture management } \\
\text { a. Check common moisture sites frequently and keep skin clean and dry }\end{array}$ & 2 & 4.7 & 18 & 41.9 & 23 & 53.5 \\
\hline b. Apply a protective cream to create a moisture barrier for all diapered children & 5 & 11.6 & 18 & 41.9 & 20 & 46.5 \\
\hline $\begin{array}{l}\text { 6-Nutritional assessment } \\
\text { a. Evaluate the child's nutritional status and then maintain it at an optimal level. }\end{array}$ & 3 & 7.0 & 9 & 20.9 & 31 & 72.1 \\
\hline b. Consult with a nutritionist as soon as possible & 4 & 9.3 & 9 & 20.9 & 30 & 69.8 \\
\hline
\end{tabular}


Table 4. Continued.

\begin{tabular}{|c|c|c|c|c|c|c|c|c|}
\hline \multirow{3}{*}{ Compliance items } & \multicolumn{6}{|c|}{ Post intervention $(n=43)$} & \multirow{3}{*}{$\mathbf{X}^{2}$} & \multirow{3}{*}{ P value } \\
\hline & \multicolumn{2}{|c|}{$\begin{array}{l}\text { Comply } \\
\text { satisfactory }\end{array}$} & \multicolumn{2}{|c|}{$\begin{array}{l}\text { Comply } \\
\text { unsatisfactory }\end{array}$} & \multicolumn{2}{|c|}{ Not comply } & & \\
\hline & No & $\%$ & No & $\%$ & No & $\%$ & & \\
\hline \multicolumn{9}{|l|}{ 1-Head to toe skin assessment } \\
\hline $\begin{array}{l}\text { a. A comprehensive skin assessment on admission and then } \\
\text { at least every shift. }\end{array}$ & 29 & 67.4 & 9 & 20.9 & 5 & 11.6 & 1.026 & $.906(\mathrm{P}>0.05)$ \\
\hline $\begin{array}{l}\text { b. Risk assessment should be done at least daily. Using the } \\
\text { Braden Scale. }\end{array}$ & 31 & 72.1 & 9 & 20.9 & 3 & 7.0 & 6.359 & $.174(\mathrm{P}>0.05)$ \\
\hline $\begin{array}{l}\text { c. Perform physical examination of skin on each turning } \\
\text { /reposition maneuver. }\end{array}$ & 31 & 72.1 & 10 & 23.3 & 2 & 4.7 & 7.02 & $.135(\mathrm{P}>0.05)$ \\
\hline d. Assess skin colour, turgor, moisture status, temperature & 32 & 74.4 & 9 & 20.9 & 2 & 4.7 & 11.662 & $.020(\mathrm{P}<0.05)^{*}$ \\
\hline $\begin{array}{l}\text { e. Document skin assessment in the child's medical record } \\
\text { 2-Medical Devices Care }\end{array}$ & 33 & 76.7 & 5 & 11.6 & 5 & 11.6 & 1.913 & $.752(\mathrm{P}>0.05)$ \\
\hline $\begin{array}{l}\text { a. Assess skin in contact with medical devices each shift or } \\
\text { more frequently with other care }\end{array}$ & 34 & 79.1 & 6 & 14.0 & 3 & 7.0 & 3.453 & $.485(\mathrm{P}>0.05)$ \\
\hline b. Rotate pulse oximeter every 8 hours or more often able & 34 & 79.1 & 6 & 14.0 & 3 & 7.0 & 10.783 & $.029(\mathrm{P}<0.05)^{*}$ \\
\hline $\begin{array}{l}\text { c. Examine the skin under equipment with routine removal } \\
\text { (e.g., restraints, splints, oxygen tubing, endotracheal tubes). }\end{array}$ & 36 & 83.7 & 4 & 9.3 & 3 & 7.0 & 3.64 & $.457(\mathrm{P}>0.05)$ \\
\hline $\begin{array}{l}\text { 3-Child positioning and bed elevation } \\
\text { a. Turn all immobile children at least every } 2 \text { hours }\end{array}$ & 37 & 86.0 & 5 & 11.6 & 1 & 2.3 & 16.983 & $.002(\mathrm{P}<0.001)^{* *}$ \\
\hline $\begin{array}{l}\text { b. If the child spends a lot of time in bed, try to move him at } \\
\text { least once every shift. If possible }\end{array}$ & 14 & 32.6 & 25 & 58.1 & 4 & 9.3 & 15.186 & $.004(\mathrm{P}<0.001)^{* *}$ \\
\hline $\begin{array}{l}\text { c. Maintain head of bed less than or equal } 30 \text { degree unless } \\
\text { contraindicated }\end{array}$ & 27 & 62.8 & 10 & 23.3 & 6 & 14.0 & 9.292 & $.054(\mathrm{P}<0.05)^{*}$ \\
\hline 4-Appropriate support surface & & & & & & & & \\
\hline $\begin{array}{l}\text { a. Use pillows or pressure reduction devices to cushion bony } \\
\text { prominences }\end{array}$ & 30 & 69.8 & 7 & 16.3 & 6 & 14.0 & 16.519 & $.002(\mathrm{P}<0.001)^{* *}$ \\
\hline $\begin{array}{l}\text { b. Each time you lift a child or provide care, look at the } \\
\text { exposed skin, especially on bony prominences }\end{array}$ & 31 & 72.1 & 9 & 20.9 & 3 & 7.0 & 4.059 & $.398(\mathrm{P}>0.05)$ \\
\hline $\begin{array}{l}\text { c. Pay special attention to areas where the child lacks } \\
\text { sensation to feel pain or has had a breakdown in the past }\end{array}$ & 19 & 44.2 & 20 & 46.5 & 4 & 9.3 & 16.327 & $.003(\mathrm{P}<0.001)^{* *}$ \\
\hline $\begin{array}{l}\text { 5-Moisture management } \\
\text { a. Check common moisture sites frequently and keep skin } \\
\text { clean and dry }\end{array}$ & 25 & 58.1 & 4 & 9.3 & 14 & 32.6 & 26.922 & $.000(\mathrm{P}<0.001)^{* *}$ \\
\hline $\begin{array}{l}\text { b. Apply a protective cream to create a moisture barrier for } \\
\text { all diapered children } \\
\text { 6-Nutritional assessment }\end{array}$ & 22 & 51.2 & 18 & 41.9 & 3 & 7.0 & 20.088 & $.000(\mathrm{P}<0.001)^{* *}$ \\
\hline $\begin{array}{l}\text { a. Evaluate the child's nutritional status and then maintain it } \\
\text { at an optimal level. }\end{array}$ & 24 & 55.8 & 16 & 37.2 & 3 & 7.0 & 14.513 & $.006(\mathrm{P}<0.001)^{* *}$ \\
\hline b. Consult with a nutritionist as soon as possible & 24 & 55.8 & 16 & 37.2 & 3 & 7.0 & 20.933 & $.000(\mathrm{P}<0.001)^{* *}$ \\
\hline
\end{tabular}

A highly statistical significant at $\mathrm{P}$ value $<0.001^{* *}$, A statistically significant difference $(\mathrm{P}<0.05)^{*}$, no statistically significant difference $(\mathrm{P}>0.05)$.

Table 5. Distribution of the studied nurses according to their total knowledge and compliance pre and post bundle implementation (N=43).

\begin{tabular}{|c|c|c|c|c|c|c|}
\hline \multirow{2}{*}{ Items } & \multicolumn{2}{|c|}{ Pre intervention $(n=43)$} & \multicolumn{2}{|c|}{ Post intervention $(n=43)$} & \multirow{2}{*}{$\mathbf{X}^{2}$} & \multirow{2}{*}{ P value } \\
\hline & No & $\%$ & No & $\%$ & & \\
\hline \multicolumn{7}{|l|}{ Total knowledge level } \\
\hline Good $(75-\geq 100 \%)$ & 7 & 16.3 & 29 & 67.5 & \multirow{4}{*}{20.010} & \multirow{3}{*}{$\mathrm{P}<0.000^{* *}$} \\
\hline Average $(60-\geq 75 \%)$ & 25 & 58.1 & 9 & 20.9 & & \\
\hline Poor $(0>60 \%)$ & 11 & 25.6 & 5 & 11.6 & & \\
\hline \multicolumn{6}{|l|}{ Total Compliance level } & \\
\hline Satisfactory Compliance & 2 & 4.7 & 32 & 74.4 & 35.372 & $\mathrm{P}<0.000^{* *}$ \\
\hline Unsatisfactory Compliance & 41 & 95.3 & 11 & 25.6 & & \\
\hline
\end{tabular}

Highly statistical significant at $\mathrm{P}$ value $<0.001 * *$

Table 6. Correlation between total knowledge score and total compliance score of the studied nurses pre and post intervention (N=43).

\begin{tabular}{lllll}
\hline \multirow{3}{*}{ Variables } & \multicolumn{2}{l}{ Pearson correlation coefficient } \\
\cline { 2 - 5 } & \multicolumn{2}{l}{ Total knowledge score } & & \\
\cline { 2 - 5 } & Pre intervention $(\mathbf{n}=\mathbf{4 3 )}$ & $\mathbf{P}$ & Post intervention (n=43) \\
\cline { 2 - 5 } & $\mathbf{r}$ & $.000^{* *}$ & $\mathbf{r}$ & .000 \\
\hline Total compliance score & .472 & .638 & $.000^{* *}$ \\
\hline
\end{tabular}

A highly statistical significant at $\mathrm{P}$ value $<0.001 * *$ 
Table 7. Comparison between study and control groups regarding stages of pressure ulcer $(N=70)$.

\begin{tabular}{|c|c|c|c|c|c|c|c|c|c|c|c|c|c|c|}
\hline \multirow{3}{*}{$\begin{array}{l}\text { Modified } \\
\text { Braden scale }\end{array}$} & \multicolumn{6}{|c|}{ Control group } & \multicolumn{6}{|c|}{ Study group } & \multirow{3}{*}{$X^{2}$} & \multirow{3}{*}{ P value } \\
\hline & \multicolumn{2}{|c|}{$\begin{array}{l}1^{\text {st }} \text { week of } \\
\text { admission }\end{array}$} & \multicolumn{2}{|c|}{$\begin{array}{l}2^{\text {nd }} \text { week of } \\
\text { admission }\end{array}$} & \multicolumn{2}{|c|}{$\begin{array}{l}\text { Before } \\
\text { discharge }\end{array}$} & \multicolumn{2}{|c|}{$\begin{array}{l}1^{\text {st }} \text { week of } \\
\text { admission }\end{array}$} & \multicolumn{2}{|c|}{$\begin{array}{l}2^{\text {nd }} \text { week of } \\
\text { admission }\end{array}$} & \multicolumn{2}{|c|}{$\begin{array}{l}\text { Before } \\
\text { discharge }\end{array}$} & & \\
\hline & No & $\%$ & No & $\%$ & No & $\%$ & No & $\%$ & No & $\%$ & No & $\%$ & & \\
\hline No risk & 4 & 11.4 & 3 & 8.6 & 5 & 14.3 & 16 & 45.7 & 14 & 40.0 & 17 & 48.5 & & \\
\hline Mild risk & 5 & 14.3 & 6 & 17.1 & 7 & 20.0 & 12 & 34.3 & 15 & 42.8 & 14 & 40.0 & & \\
\hline Moderate risk & 7 & 20.0 & 9 & 25.8 & 10 & 28.6 & 4 & 11.4 & 3 & 8.6 & 3 & 8.6 & 5.387 & $\begin{array}{l}0.05 * \\
\mathrm{P}\end{array}$ \\
\hline High risk & 13 & 37.2 & 15 & 42.8 & 10 & 28.6 & 2 & 5.7 & 2 & 5.7 & 1 & 2.9 & & \\
\hline Severe risk & 6 & 17.1 & 2 & 5.7 & 4 & 11.4 & 1 & 2.9 & 1 & 2.9 & 0 & 0.0 & & \\
\hline
\end{tabular}

$* A$ statistically significant difference $(P \leq 0.05)$

\section{Discussion}

The prevention of pressure ulcer (PU) requires the accurate identification of children at risk and the reliable implementation of prevention strategies in children identified as being at risk [16]. The prevention of PU depends on the clinical ability to assess the level of risk of PU development in order to design a prevention program. The nurse's clinical judgment is fundamental in this process; however, several instruments have been developed to identify the risk factors and thereby refine this assessment, individualizing the care and optimizing prevention costs [17]. As in adults, many factors contribute to skin breakdown and pressure ulcers in children duration and amount of pressure, friction, shear, moisture, perfusion, malnutrition, infection, anemia, and immobility [18].

Therefore, the aim of the present study was to evaluate the effect of preventive bundle guidelines on nurses' knowledge and compliance regarding pressure ulcer among critically ill children in Pediatric Intensive Care Unit. This aim was achieved throughout the study findings and the research hypotheses were accepted.

Regarding nurses' characteristics, the findings of the current study revealed that the highest percentage of studied nurses were females. This result was in the same line with Hassan [19], who conducted a study entitled "Impact of educational guidelines about prevention of pressure injuries among infants in intensive care unit" who found that the majority $84 \%$ of studied nurses were females.

The result of the current study clarified that two fifth of the studied nurses had years of experience more than 8 years. This finding didn't agree with Zhang et al., [20] in the study about "Assessing nursing quality in pediatric intensive care units: a cross ${ }^{-}$sectional study in China" who found that more than $30 \%$ of the nurses in this study had worked in PICUs for fewer than 3 years, and added that young nurses do not have proficient clinical skills. They have less awareness of safety, and they are deficient of experience in managing and prioritizing child care needs, caring for critical ill children and predicting problems early. Therefore, young nurses need special PICU training. From the researchers' point of view, years of experience in pediatric intensive care unit have a great effect on nurses' knowledge and compliance which result in improving optimal performance in all nursing aspects of their field.

Regarding children's characteristics, the finding of the current study found that less than one third of the studied children age $6>12$ years and more than half of them were males. This agrees with the results of Curley et al., [16] who conducted a study of "Predicting pressure injury risk in pediatric patients: The Braden QD Scale" and found that less than one third (31\%) of the studied children ' was more than 8 years and more than half $(53 \%)$ of the studied children were males.

On assessing nurses' knowledge about pressure ulcer, the findings of the current study reflected that, the minority of the studied nurses had good knowledge pre intervention this increased to more than two thirds of them had good knowledge post intervention. This finding was consistent with Hassan [19]., who found that only $2 \%$ of nurses had satisfactory knowledge before intervention and the majority of them had satisfactory knowledge after intervention. This finding goes in line with Al-Shidi, [21] who conducted a study to explore the nurses' level of knowledge in relation to prevention and management of pressure ulcer in Oman and revealed that, nurses had a low level of knowledge regarding management and prevention of pressure ulcers. In addition, this finding is in agreement with Abou El Enein \& Zaghloul, [22] who assess nurses' knowledge of prevention and management of pressure ulcer at a health insurance hospital in Alexandria and illustrated that, nurses had a poor level of knowledge regarding prevention and management of pressure ulcer.

However, after implementation of the guideline, there was a significant improvement in the total scores of nurses who achieve a good level of knowledge. This finding is matched with the hypothesis number one. The improvement scores indicated that, the bundle was a successful method to increase nurses' knowledge about pressure ulcer. This finding on the same line with findings of Hashad \& Hassan, [23] who conducted a study to evaluate the effect of implementing a designed skin care bundle protocol on modifying nurses' practices towards pediatric intensive care unit patients and revealed that high percentage $(71.4 \%)$ of nurses' had a significant good sufficient knowledge about pressure ulcer and skin care bundle after program implementation.

Regarding nursese Compliance with preventive bundle guidelines, there was an improvement of nurses' compliance after the bundle implementation. This finding matches with 
the hypothesis number one. From researchers' points of view, this improvement was significantly associated with more familiarity and understanding of the bundle guidelines. This finding is consistent with Tayyib et al., [24] who conducted a study to appraise the implementation of a pressure ulcer prevention bundle in an adult intensive care and demonstrated a highly significant level of compliance among nurses after the pressure ulcer prevention bundle implementation (78.1\%). Meanwhile, Visscher et al., [25] mentioned in their study about implementing a qualityimprovement intervention to reduce pressure ulcer in pediatric intensive care units that, nurses' compliance averaged $81 \%$ in the pediatric intensive care unit.

At the same point of view, Horner\& Bellamy, [26] supported that, more educational sessions and continuous training, evaluation and the provision of feedback to the nurses will increase understanding of the intervention and familiarity with the bundle, which in turn lead to an increased compliance to the intervention.

Concerning the correlation between total nurses' knowledge and compliance score after use of bundle implementation. The present study illustrates that, there was a positive correlation between total nurses' knowledge and compliance scores after bundle implementation. This finding matches with the hypothesis number two. This result is congruent with Beeckman et al., [27] who conducted a study to assess knowledge and attitudes of nurses on pressure ulcer prevention: a cross-sectional multicenter study in Belgian hospitals and found that, nurses' knowledge is positively associated with evidence-based compliance.

This finding is similar to Konstantin, [28] who conducted a study to evaluate the effectiveness of the unit- based skin care intervention in pediatric intensive care unit and found that, $67 \%$ of the nurses agreed they were more knowledgeable about pressure injury prevention methods, and $66 \%$ of them strongly agreed that a unit-specific skincare-intervention would be beneficial in preventing pressure injuries.

On the same line, Sabaq \&Amer [29] in the study about the effect of preventive bundle guidelines on reducing iratogenic pressure injury among critically ill neonates and found that, there was a positive correlation between nurses knowledge and their compliance after bundle implementation $(\mathrm{r}=.657, \mathrm{P}<0.001)$. Moreover, Riccioni et al., [30] stated that pressure ulcer prevention continues to be a hot topic in pediatric hospitals. Pressure ulcer considered to be a nursingsensitive indicator because the occurrence and outcome are most affected by nursing care.

Concerning the risk of pressure ulcer occurrence in the studied children, according to Braden scale, The present study showed that, preventive bundle guidelines were significantly reduced the pressure ulcer risk among study group compared with the control group evidence by there were a statistical significant difference between control and study group. These findings support the hypothesis number three. This finding supported by Uysal et al., [2] on the study done about "Effect of pressure injury prevention guides used in pediatric intensive care" who found that there were a statistical significant difference between control and study group ( $\mathrm{P}<0.001)$. However, Liao et al., [31] mentioned that Pediatric pressure ulcers are a serious problem to healthcare service. Thus, effective and early identification of the risk of developing pressure ulcer is essential.

From the researchers' point of view, these findings add more support for applying the prevention bundle guidelines to prevent pressure ulcer because they allow rapid spread of best practices among nurses result in improving their compliance and clinical outcomes. These findings are in harmony with a study carried out by Frank et al., [14] to describe change in pressure injury rate in pediatric hospitals after implementation of pressure injury prevention bundle and revealed that, there was a significant reduction of pressure injuries especially stage three and four after implementation of elements of prevention bundle. Additionally, Tayyib et al., [24] who carried out a study to determine the effectiveness of a pressure ulcer prevention bundle for critically ill patients and illustrated that, prevention bundle helps in reducing pressure ulcer in the intervention group $17.1 \%$ as compared with $52.8 \%$ in the control group. In this context, Penoyer et al., [32] concluded that using the ICU specific pressure ulcer prevention resulted in fewer hospital acquired pressure ulcer in ICU patient.

Moreover, Crane et al., [33] added that critically ill children admitted to pediatric ICU are at high risk for developing pressure injuries and this risk increased without intervention.

The present study revealed that more than one third of control group were at high risk on the first week of admission. This finding didn't agree with Curley et al., [16] who indicated that only $18 \%$ at risk on admission.

\section{Conclusion}

Based on the results of the present study, it can be concluded that, the implementation of preventive bundle guidelines proved to be effective in improving nurses' knowledge and their compliance, with a positive impact on the incidence of pressure ulcer among critically ill children.

\section{Recommendation}

In the light of the findings of the current research, the following recommendations are suggested: 1. Provide continuous education and training sessions for nurses working at pediatric intensive care units about pressure ulcer prevention to improve their knowledge and compliance. 2. The availability of printed bundle guidelines about pressure ulcer prevention and management will result in significantly better outcomes. 3. Emphasize multidisciplinary collaboration to reliably implement bundle in an effort to reduce pressure ulcer in pediatric intensive care units. 4 . The importance of quality improvement and child safety collaboration available to care providers within pediatric critical care. 


\section{Acknowledgements}

The researchers thank first Allah and would like to express gratitude and appreciations to the head of the pediatric intensive care unit in the study setting, and the nurses for their genuine, cooperation and arrangements to achieve the research methodology as designed.

\section{References}

[1] Simsic J., Kevin D., Sarah H., Stephanie P. \&Robert G., (2019): Prevention of pressure ulcers in a pediatric cardiac intensive care unit, Pediatric Quality \& Safety, 2 April, 2019 - Volume 4 Latest Articles - Issue 2- p, Wolters Kluwer.

[2] Uysal G., Duzkaya D. S., Yakut T. \& Bozkurt G., (2019): Effect of pressure injury prevention guides used in a pediatric intensive care, Clinical Nursing Research, PP: 1-14.

[3] Kiss E. \& Heilar M. (2014): Pediatric skin integrity practice guideline for institutional use: A quality improvement project Journal of Pediatric Nursing 29, 362-367.

[4] Özgen R., \& Eti Aslan F., (2015): Evaluation of pressure wound prevalence and risk factors in children (master thesis). Acibadem University, İstanbul.

[5] Sterken D. J., Mooney J., Ropele D., Kett A., \&Vander Laan K. J., (2015): Mastering pressure ulcer risk assessment with the pediatric pressure ulcer prediction and evaluation tool (PPUPET), Journal of Pediatric Nursing, 30, 598-610.

[6] Goodman L., Khemani E., Cacao F., Yoon J., Burkoski V., Jarrett S., Collins B. \& Hall T., (2018): A comparison of hospital-acquired pressure injuries in intensive care and nonintensive care units: a multifaceted quality improvement initiative, PMJ, Volume 7, Issue 4.

[7] Singh C. D., Anderson C., White E. \& Shoqirat, N. (2018): The impact of pediatric pressure injury prevention bundle on pediatric pressure injury rates, Journal of Wound, Ostomy and Continence Nursing, 45, 209-212.

[8] Schlüer A. B., (2017): Pressure ulcers in maturing skin-A clinical perspective. Journal of Tissue Viability.; 26 (1): 2-5. Doi: $10.1016 /$ j.jtv.2016. 10.001

[9] Courtwright S. E., Mastro K. A., Preuster C., Dardashti N., McGill S. \& Madelon M., (2017): Reducing hospital-acquired pressure ulcers using bundle methodology in pediatric and neonatal patients receiving extracorporeal mem brane oxygenation therapy: An integrative review and call to action. Journal for Specialists in Pediatric Nursing. 22 (4). Doi: 10.1111/jspn.12188.

[10] Al-Otaibi Y. K., Al-Nowaiser N. \& Rahman A., (2019): Reducing hospital-acquired pressure injuries, BMJ Open Quality, 26 April, 2019.

[11] Padula W. V., Pronovost P., Makic M. B., Wald H., Moran D., Mishra M. K. \& Meltzer D. O., (2019): Value of hospital resources for effective pressure injury prevention: a costeffectiveness analysis, BMJ, Volume 28, Issue 2.

[12] Zuo X. \& Meng F. A., (2015): A care bundle for pressure injury treatment in intensive care units. International Journal of Nursing Sciences, 2; (4): 340-347. December 2015, Doi: 10.1016/j.ijnss. 10.008 .

[13] Vasconcelos B. D. J. \& Caliri L. H. M., (2017): Nursing actions before and after a protocol for preventing pressure injury in intensive care, Escola Anna Nery; 21 (1). Doi: 10.5935/1414-8145.20170001.

[14] Frank G., Walsh K. E., Wooton S., Bost J., Dong W., Keller L., Miller M., Zieker K. \& Brilli B. J., (2017): Impact of a pressure injury prevention bundle in the solutions for patient safety network, Pediatric Quality\& Safety. April 2017, Volume 2 , Issue 2 .

[15] Quigley S. M. \& Curley M. A., (1996): Skin integrity in the pediatric population: Preventing and managing pressure ulcers. Journal of the Society of Pediatric Nurses. 1996; 1 (1): $7-18$.

[16] Curley M. A., Hasbani N. R., Quigley S. M., Stellar J. J., Pasek T. A. \& Shelley S. S., (2018): Predicting pressure injury risk in pediatric patients: The Braden QD Scale, The journal of pediatric, 192: 189-95.

[17] Santos V. L., Serpa L. F., Cordero G. M. \& Gamboa S. G., (2018): Risk assessment in pressure ulcers, science and practice of pressure ulcer management, Springer publisher, $\mathrm{pp}$ 57-77.

[18] Reyna R., (2015): Preventing pressure ulcers in pediatric patients, Practical Issues in Wound, Skin and Ostomy Management, available at https://woundcareadvisor.com/preventing-pressure-ulcers-inpediatric-patients_vol4-no4.

[19] Hassan E. A., (2018): Impact of educational guidelines about prevention of pressure injuries among infants in intensive care unit, Symbiosis Journal Nursing health care, semantic scholar, available at https://www.semanticscholar.org/faq.

[20] Zhang Y., Liu L., Hu J., Wang Z. \& Haung Q., (2016): Assessing nursing quality in paediatric intensive care units: a cross-sectional study in China, Nursing in critical care, Volume 22, Issue 6, 355-361.

[21] Al-Shidi A. S., (2016): Pressure ulcer management in Oman: Nurses' knowledge and views, Dissertation submitted in partial fulfillment of the requirements for the degree of doctorate of philosophy in nursing and Health care, School of medicine, Collage of medical, veterinary \& life sciences, Glasgow University.

[22] Abou- El Enein N. Y., \& Zaghloul A. A., (2011): Nurses' knowledge of prevention and management of pressure ulcer at a Health Insurance Hospital in Alexandria, International Journal of Nursing Practice 2011; 17 (3): 262-268.

[23] Hashad R., E. \& Hassan R. E., (2018): The effect of implementing a designed skin care bundle protocol on modifying nurses' practices toward pediatric intensive care units patients. International Journal of Nursing Didactics. 2018; 8 (2): 33-40.

[24] Tayyib N., Coyer F. \& Lewis P. A., (2016): Implementing a pressure ulcer prevention bundle in an adult intensive care. Intensive and Critical Care Nursing. 2016b; (37): 27-36.

[25] Visscher M., King A., Nie A., Schaffer P., Taylor T., Pruitt D., Giaccone M., Ashby M. \&Keswani S. A., (2013): Qualityimprovement collaborative project to reduce pressure ulcers in PICUs, Official Journal of The American Academy of Pediatrics. 2013; 131 (6): 1950-1960. 
[26] Horner D., L., \& Bellamy M., C., (2012): Care bundles in intensive care. Continuing Education in Anesthesia Critical Care \& Pain. 2012; 12 (4), 199-202.

[27] Beeckman D., Defloor T., Schoonhoven L., \&Vanderwee K., (2011): Knowledge and attitudes of nurses on pressure ulcer prevention: a cross-sectional multicenter study in Belgian hospitals. Worldviews Evidence Based Nursing. 2011; 8 (3): 166-176. doi: 10.1111/j.17416787.2011.00217.x.

[28] Konstantin A. T., (2017): Pediatric intensive care unit skincare team. Master s' projects and Capstone. 2017, University of San Francisco, available at https://respiratory.usfca.edu/capstone/508.

[29] Sabaq A. G. \& Amer S. A., (2018): Effect of preventive bundle guidelines on reducing iatrogenic pressure injuries among critically ill neonates, International Journal of Nursing Didactics, 8: (08) 22-36, August (2018).
[30] Riccioni R., Berlanga R., Hagan J., Schier R. \&Gordon M., (2019): Interrater reliability of the Braden and Braden Q by skin champion nurses, Journal of Pediatric Nursing, Volume 44, January-February 2019, Pages 9-15.

[31] Liao Y., Gao G. \& Mo L., (2018): Predictive accuracy of the Braden Q Scale in risk assessment for pediatric pressure ulcer: A meta-analysis, International journal of nursing science, Volume 5, Issue 4, 10 October 2018, Pages 419-426.

[32] Penoyer D., Britt C., Arwood L., Wilkinson L. \& Sole M., (2019): A critical care-specific pup bundle reduces hospitalacquired pressure ulcers in the ICU, Critical Care Medicine: January 2019 - Volume 47 - Issue 1 - p 324.

[33] Crane N., Pool N., Chang I. \& Rogan S., (2019): A dedicated pediatric logistic organ dysfunction score - adjusted pressure injury risk assessment scale is required for tertiary pediatric ICUs, cardiology in the young, volume 29, Issue 3 March 2019, pp. 455-456. 